\title{
Does an Intervention Program on the Violence Against Employees Preserve the Nursing Traditional Role?
}

\author{
Isaak $\mathrm{V}^{* 1}$ and Steiner Lavi $\mathbf{0}^{2}$ \\ ${ }^{1}$ The Division of Public Administration and Policy University of Haifa, Israel
}

${ }^{2}$ Management Faculty, MLA The College for Academic Studies, Israel

Received: 眥: November 20, 2018; Published: 制: December 12, 2018

*Corresponding author: Isaak V, The Division of Public Administration and Policy, School of Political Sciences, University of Haifa, Mount Carmel, Haifa 31905, Israel

\begin{abstract}
Background: This study explores an intervention program aims to reduce the employees' risk of injury due to patient violence in forensic psychiatric hospital.

Method: The safety intervention program that consisted of a three days' workshop was conducted in the maximum - security ward of a psychiatric hospital in Israel. The study examines the effect of the intervention program over a period of ten years in four wards.

Results: Analysis of the data demonstrates that the intervention program along with the training had a long-term effect, reducing both the number of violent incidents and the number of actual employee injuries in forensic psychiatric hospital.

Conclusion: We conclude that although such an intervention program is essential for the employees' wellbeing, it changes the traditional role of nursing care, and an alternative program should be conducted.

Keywords: Violence at Work; Intervention Program; Care and Control Behaviour; Public Sector Mental Healthcare

Abbreviations: OSHA: Occupational Safety and Health Administration; MHC: Maximum-Security Unit; IDF: Israeli Défense Force; CBT: Cognitive Behavioural Therapy Groups
\end{abstract}

\section{Introduction}

\section{Violence in the Mental Health System}

Mental patient violence has been described as "The dark side of mental disorders" [1,2] with high rates of violent incidents in psychiatric institutions. Studies in the United States, Canada, Belgium, and Australia show that $26 \%$ - 56\% of hospital and community agency staff who treat psychiatric patients have been victims of assault $[3,4]$. The concomitant implications of these incidents are physical pain, emotional suffering and impaired therapeutic relations as well as high financial costs for the organization [5,6]. Hillebrand, Forster, and Spitz (1996) [7] reported that over $2 \%$ of maximum-security forensic hospital budgets in the United States were directed to salaries for employees hired to replace personnel absent due to patient-inflicted injuries and there are indications that the magnitude of workplace violence is steadily increasing [8]. In most cases, nurses are the victims of such violence [9-12]. A recent study in Poland found higher rates of violent incidents against psychiatric nurses compared to nurses in other medical disciplines [8]. In the United States, reports suggest that one in four psychiatric nurses are assaulted by patients and require work absence each year [13].

An Australian study, conducted on closed psychiatric wards, found that $78 \%$ of the victims of patient assaults were nurses, $4 \%$ were physicians, $2 \%$ were psychologists, and $2 \%$ were social workers [4]. The difference was explained by the nurses' constant attendance to the patients. In addition, nurses are those who provide primary treatment for violent patients, especially during outbursts $[10,12,14]$. As a result, nurses in forensic units describe their work as an ongoing conflict between their desire to assist patients, as expected of nurses, and their need to avoid harm by patients [15]. As a result of this phenomena, for the last two decades, the United 
States Occupational Safety and Health Administration (OSHA) has stressed psychiatric institution are responsible for maintaining safety standards toward minimizing occupational injuries $[5,6]$. Alongside these policies various interventions aimed at reducing violence toward employees, either specifically in psychiatric facilities or generally in workplaces have been proposed $[15,16]$.

\section{Intervention Programs to Reduce Violence Against Employees}

Several different interventions have been proposed and studied with the aim of minimizing employee injuries. These interventions include structured feedback after violent events and violence management teams [16,17]. Studies have assessed these interventions in hospitals reporting their success [17-21]. Other interventions have focused on staff training toward managing patient aggression [22,23]. Finally, designing environments with fewer risk factors (e.g. ensuring patients and staff can be seen at all times) is another intervention that has been implemented and studied [24,25]. Recently, Isaak, Vashdi, Bar-Noy, Kostisky, Hirschman, and Grinshpoon, (2017) [26] proposed a new intervention combining many of the aspects learnt from previous interventions. They found that their specific intervention enhanced a safety climate in the relevant hospital wards and showed a reduction in both the number of aggressive incidents towards employees and in the number of employee injuries. Thus, most of these studies focused on how these interventions reduce violent incidents or employee injuries. Yet these studies did not examine the long-term effects of these interventions, mostly conducting a "before and after" research program. In the current study, we examine if there is a long-term effect of the intervention proposed in Isaak et al. [26] that may have a prolonged impact continuing to reduce injuries and violent incidents.

\section{Method}

We returned to the same hospital where the study conducted by Isaak et al. [26] took place. In their study, they examined the effect of a three days intervention called the "Getting Home Safely" in a Mental Health Clinic's (MHC) maximum-security unit in Israel. The intervention program was delivered to the entire staff of the forensic psychiatry departments Isaak et al.

The intervention program is a three days program including the following:

a) Day one - Personal Safety: Participants learn how to avoid dangerous situations, self-defense skills, and methods for safely restraining patients.

b) Day two - Participants learn how to use tools for better inter-staff communication.

c) Day three - Organizational Learning. Participants learn how to conduct incident investigations after adverse events based on the model used by the IDF (Israeli Défense Force).

In order to maintain the outcomes of the intervention program, since 2009 training sessions have been conducted on a regular basis each year. The staff decides which module day (i.e., personal safety, communication, or organizational learning) to emphasize each year. Each department manager receives notification of the need for a training in his department from his supervisor. The department manager conducts a survey among all the employees, and based on their choice, the selected topic was presented at the training.

\section{Sample and Procedure}

Based on organizational reports, we received additional data presented in Isaak et al. [26] regarding violent incidents in the MHC's four maximum-security units in the ten years following the initial intervention. In addition, we received absenteeism days regarding all staff for the whole period from 2007, when the intervention was initially conducted, to 2017. In the four maximum-security units there are 112 employees (according to the HR division reports, there is a fixed number of employees in this four units with no changes over the period between 2007 and 2017) (Table 1).

Table 1: Demographic Characteristics of Hospital Staff.

\begin{tabular}{|c|c|c|c|c|c|c|c|c|c|}
\hline \multicolumn{10}{|c|}{ Demographic Characteristics of Hospital Staff. } \\
\hline \multicolumn{2}{|c|}{ Gender } & \multicolumn{2}{|c|}{ Sector } & \multicolumn{2}{|c|}{ Education } & \multicolumn{2}{|c|}{$\begin{array}{c}\text { Seniority in Unit } \\
\text { (years) }\end{array}$} & \multicolumn{2}{|c|}{$\begin{array}{c}\text { Seniority in Organization } \\
\text { (Years) }\end{array}$} \\
\hline Male & $47.4 \%$ & Doctor & $7.14 \%$ & High school & $43.1 \%$ & Up 1 & $18.6 \%$ & Up 1 & $10.6 \%$ \\
\hline \multirow[t]{4}{*}{ Female } & $52.6 \%$ & Nurse & $71.43 \%$ & Bachelor Degree & $28.1 \%$ & $1-10$ & $42.3 \%$ & $1-10$ & $29.6 \%$ \\
\hline & & $*$ Other & $21.43 \%$ & Master Degree & $15.6 \%$ & $11-20$ & $24.4 \%$ & $11-20$ & $37.3 \%$ \\
\hline & & & & \#Other & $13.1 \%$ & $21-30$ & $7.7 \%$ & $21-30$ & $16.9 \%$ \\
\hline & & & & & & $31-40$ & $7.1 \%$ & $31-40$ & $5.6 \%$ \\
\hline
\end{tabular}

*Other = psychologists, social workers, occupational therapists, maintenance workers, and secretaries.

\#Other = Psychiatric graduate nursing course.

\section{Research Variables}

\section{Number of Incidents}

Aggressive or violent incidents were defined as cases in which a patient physically attacked a staff member. The data was drawn from internal reports submitted to the Risk Management Director.

\section{Number of Absenteeism Days}

The number of days in which employees took a day of absence in each ward was examined using internal reports to the Risk Management Director. 


\section{Results}

As can be seen in Table 2, beyond the decreese already shown in Isaak et al. [26], there is a rather steady decrease in the number of violent incidents throughout the maximum-security unit from 2013 to 2017. The rate of incidents is kept low in comparison to the pre-intervention years. Table 3 presents decreased absenteeism days. In 2006, prior to the intervention program, the injured led to 797 absence days in total at the four units. After the intervention program had been conducted, we can see a reduction of absence days that represents a long-term effect (leading to 176 absence days in 2017) (Tables 1 \& 2).

Table 2: The Number of Aggressive Incidents towards Staff before and after the Intervention in all Four Forensic Units.

\begin{tabular}{|c|c|c|c|c|c|c|c|c|c|c|c|c|c|c|}
\hline \multicolumn{15}{|c|}{$\begin{array}{l}\text { The Number of Aggressive Incidents towards Staff before and after the } \\
\text { Intervention in all Four Forensic Units }\end{array}$} \\
\hline \multicolumn{4}{|c|}{ Before the Intervention Program } & \multicolumn{11}{|c|}{ After the Intervention Program } \\
\hline Year & 2004 & 2005 & 2006 & 2007 & 2008 & 2009 & 2010 & 2011 & 2012 & $2013 a$ & 2014 & 2015 & 2016 & 2017 \\
\hline $\begin{array}{l}\text { Number of } \\
\text { Incidents* }\end{array}$ & 13 & 19 & 55 & 36 & 26 & 18 & 8 & 14 & 12 & 13 & 10 & 6 & 16 & 13 \\
\hline
\end{tabular}

*Incidents include accident with and without physical injury.

aAll data up until this point was presented in Isaak et al., 2017.6

Table 3: Demographic Characteristics of Hospital Staff.

\begin{tabular}{|c|c|c|c|c|c|c|c|c|c|c|c|c|c|c|}
\hline \multicolumn{15}{|c|}{ Number of Absenteeism Days } \\
\hline \multicolumn{4}{|c|}{ Before the Intervention Program } & \multicolumn{11}{|c|}{ After the Intervention Program } \\
\hline Year & 2004 & 2005 & 2006 & 2007 & 2008 & 2009 & 2010 & 2011 & 2012 & 2013 & 2014 & 2015 & 2016 & 2017 \\
\hline $\begin{array}{c}\text { Number of Absence } \\
\text { Days }\end{array}$ & 104 & 410 & 797 & 519 & 381 & 317 & 301 & 214 & 247 & 245 & 213 & 198 & 189 & 176 \\
\hline Loss of Personnel* & 0.47 & 1.86 & 3.6 & 2.3 & 1.73 & 1.44 & 1.36 & 0.97 & 1.12 & 1.11 & 0.96 & 0.9 & 0.85 & 0.8 \\
\hline
\end{tabular}

\section{Conclusion}

Previous research has shown that the "Getting Home Safely" intervention succeeded in restoring the sense of a healthy work environment for employees at the Mental Health Center, and significantly reduced the scope of violence in the wards. The corrent research makes an additional contribution by showing the positive long-term effects of the intervention program even after a decade. "Getting Home Safely" succeeded in restoring the sense of a healthy work environment for employees at the Sha'ar Menashe Health Center and significantly reduced the incidence of violence in the wards. We raise the dilemma of the right way handling the patients' violence by the nurses: In 1996, the American Nurses Association announced nursing in forensic psychiatry as a unique field of specialization in nursing. Nursing staff in legal wards is facing many difficulties and moral and ethical dilemmas are encountered in the course of their duties $[27,28]$. There is a gap between the traditional role of the psychiatric nurse and the role he or she plays in practice in the clinical field. This gap, together with the fear of potential violence in the work environment, may lead to a change in the perception of the nurse's role in a way that will reduce the therapeutic interventions that she or he is supposed to perform. Instead, they might focus on guard and security skills [27-29].

The role of the nurse is influenced from the environment in which she operates. In the departments of forensic psychiatry, there is a tendency to deal with aspects of the role of control in contrast to the characteristics expected from the nursing profession, such as care. The existence of a safe therapeutic environment in psychiatric departments is essential for the nursing staff in order to provide care based on the principles of nursing care [30]. The contrast between care and supervision requires the nursing staff to choose one approach over the other and to act accordingly [27,31,32]. This raises the question whether the management should focus on the intervention program that succeeded in reducing the violence, but by the same time led the nurses to a difference role other than patients' care, or should we look for other programs that will support the nurses staff and will give them tools that will keep the traditional role of care (such as CBT Cognitive Behavioural Therapy groups). We strongly recommend that future research will be conducted to study the effects of CBT groups or other programs after they will be implement in the forensic wards.

\section{References}

1. (1997) APA task force report, clinical safety.

2. Buchanan A, Binder R, Norko M, Swartz M (2012) Psychiatric Violence Risk Assessment. The American Journal of Psychiatry 169(3): 340.

3. Dhumad S, Wijeratne A, Treasaden I (2007) Violence against psychiatrists by patients: survey in a London mental health trust. Psychiatric Bulletin. 31(10): 371-374.

4. McKinnon B, Cross W (2008) Occupational violence and assault in mental health nursing: Scoping project for a Victorian Mental Health Service. International Journal of Mental Health Nursing 17(1): 9-17.

5. Appelbaum PS, Dimieri RJ (1995) Protecting staff from assaults by patients. OSHA steps in psychiatric services 46(4): 333-334, 338.

6. Turgut T, Lagace D, Izmir M, Dursum S (2006) Assessment of Violence and Aggression in Psychiatric Setting: Descriptive approaches. Klinik Psikofarmokoloji Bulteni 16(3): 179-194.

7. Hillbrand M, Foster HG, Spitz RT (1996) Characteristics and cost of staff injuries in a forensic hospital. Psychiatric Services 47(10): 1123-1125. 
8. Merecz D, Rymaszewska J, Moscicka A, Kiejna A, Jarosz Novac J (2006) Violence at the work place- a questionnaire survey of nurses. European Psychiatry 21(7): 442-450.

9. Chen S, Hwu HG, Williams RA (2005) Psychiatric nurse's anxiety and cognition in managing psychiatric patients' aggression. Archives of Psychiatric Nursing 19(3): 141-149.

10. Flannery RB Jr, Flannery GJ (2010) Walker AP. Time of psychiatric patient assaults: twenty-year analysis of the Assaulted Staff Action Program (ASAP). International Journal of Emergency Mental Health 12(4): 267-273.

11. Lanza ML, Zeiss R, Rierdan J (2006) Violence against psychiatric nurses: sensitive research as science and intervention. Contemporary Nurse 21(1): 71-84

12. Owen C, Tarantello C, Jones M, Tennant C (1998) Violence and aggression in psychiatric units. Psychiatric Services 49(11): 1452-1457.

13. Cameron Q (2006) Forensic psychiatric aspects of inpatient violence. Psychiatric Clinics 29(3): 743-760.

14. Yang LQ, Spector PE, Chang CH, Gallant Roman M, Powell J (2012) Psychosocial precursors and physical consequences of workplace violence towards nurses: A longitudinal examination with naturally occurring groups in hospital settings. International Journal of Nursing Studies 49(9): 1091-1102.

15. Jacob JD, Holmes D (2011) Working under threat: fear and nurse-patient interactions in a forensic psychiatric setting. Journal of Forensic Nursing $7(2): 68-77$.

\section{ISSN: 2574-1241}

DOI: $10.26717 /$ BJSTR.2018.12.002193

Isaak V. Biomed J Sci \& Tech Res

This work is licensed under Creative

Commons Attribution 4.0 License

Submission Link: https://biomedres.us/submit-manuscript.php
16. Arnetz JE, Arnetz BB (2000) Implementation and evaluation of a practical intervention program for dealing with violence towards health care workers. Journal of Advance Nursing 31(3): 668-680.

17. Brayley J, Lange R, Baggoley C, Bond M, Harvey P (1994) The violence management team. An approach to aggressive behaviour in general hospital. Medical Journal of Australia 161: 254-258.

18. Farrel G, Cubit K (2005) Nurses under threat: A comparison of content of 28 aggression management programs. International Journal of Mental Health Nursing 14(1): 44-53.

19. Flannery RB, Hanson MA, Penk WE (1994) Risk factors for psychiatric inpatient assaults on staff. Journal of Mental Health Administration 21(1): 24-31.

20. Grainger C (1993) Occupational violence: managing the risk of assault in the workplace. Journal of Occupational Health and Safety - Australia and New Zealand 9(1): 43-47.

21. Murray MG, Snyder JC (1991) When staff are assaulted. A nursing consultation support service. Journal of Nursing and Mental Health Services 29(7): 24-29.

22. Carmel H, Hunter M (1990) Compliance with training in managing assaultive behaviour and injuries from inpatient violence. Hospital and Community Psychiatry 41(5): 558-560.

23. Luria G, Morag I (2012) Safety management by walking around (SMBWA): A Safety intervention program based on both peer and manager participation. Accident Analysis and Prevention 45: 248-257.

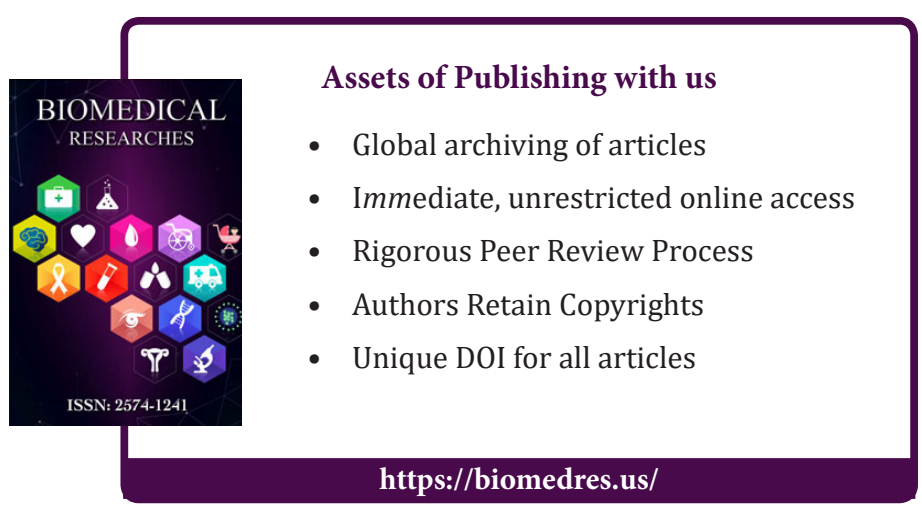

